OPEN ACCESS

Edited by:

Heike Bücking,

South Dakota State University,

United States

Reviewed by:

Jan Jansa,

Institute of Microbiology (ASCR),

Czechia

Sergio Saia

Council for Agricultural Research

and Economics, Italy

*Correspondence:

Julia Ferrar

julia.ferrari@york.ac.uk

orcid.org/0000-0001-6519-4254

tPresent address:

Thomas D. J. Wilkinson, ADAS Gleadthorpe, Mansfield,

United Kingdom

Specialty section:

This article was submitted to

Plant Microbe Interactions,

a section of the journal

Frontiers in Plant Science

Received: 05 March 2019

Accepted: 24 June 2019

Published: 12 July 2019

Citation:

Wilkinson TDJ, Miranda J-P,

Ferrari J, Hartley SE and Hodge A

(2019) Aphids Influence Soil Fungal

Communities in Conventional

Agricultural Systems.

Front. Plant Sci. 10:895

doi: $10.3389 /$ fpls.2019.00895

\section{Aphids Influence Soil Fungal Communities in Conventional Agricultural Systems}

\author{
Thomas D. J. Wilkinson ${ }^{1+}$, Jean-Pascal Miranda ${ }^{1}$, Julia Ferrari ${ }^{1 *}$, Sue E. Hartley ${ }^{1,2}$ and \\ Angela Hodge ${ }^{1}$
}

${ }^{1}$ Department of Biology, University of York, York, United Kingdom, ${ }^{2}$ York Environmental Sustainability Institute, University of York, York, United Kingdom

Arbuscular mycorrhizal fungi (AMF) form symbioses with the roots of most plant species, including cereals. AMF can increase the uptake of nutrients including nitrogen $(N)$ and phosphorus (P), and of silicon (Si) as well as increase host resistance to various stresses. Plants can simultaneously interact with above-ground insect herbivores such as aphids, which can alter the proportion of plant roots colonized by AMF. However, it is unknown if aphids impact the structure of AMF communities colonizing plants or the extent of the extraradical mycelium produced in the soil, both of which can influence the defensive and nutritional benefit a plant derives from the symbiosis. This study investigated the effect of aphids on the plant-AMF interaction in a conventionally managed agricultural system. As plants also interact with other soil fungi, the non-AMF fungal community was also investigated. We hypothesized that aphids would depress plant growth, and reduce intraradical AMF colonization, soil fungal hyphal density and the diversity of AM and non-AM fungal communities. To test the effects of aphids, field plots of barley enclosed with insect proof cages were inoculated with Sitobion avenae or remained uninoculated. AMF specific and total fungal amplicon sequencing assessed root fungal communities 46 days after aphid addition. Aphids did not impact above-ground plant biomass, but did increase the grain $\mathrm{N}: \mathrm{P}$ ratio. Whilst aphid presence had no impact on AMF intraradical colonization, soil fungal hyphal length density, or AMF community characteristics, there was a trend for the aphid treatment to increase vesicle numbers and the relative abundance of the AMF family Gigasporaceae. Contrary to expectations, the aphid treatment also increased the evenness of the total fungal community. This suggests that aphids can influence soil communities in conventional arable systems, a result that could have implications for multitrophic feedback loops between crop pests and soil organisms across the above-below-ground interface.

Keywords: arbuscular mycorrhizal fungi, community diversity, amplicon sequencing, Hordeum vulgare, Sitobion avenae, rhizosphere, multitrophic interactions

\section{INTRODUCTION}

Arbuscular mycorrhizal fungi (AMF) form obligate symbioses with the roots of c. twothirds of land plant species, including agriculturally important cereals (Smith and Read, 2008; Fitter et al., 2011). Enhancing this symbiosis has been proposed as an important tool for increasing food security and agricultural sustainability (Gosling et al., 2006; 
Fitter et al., 2011; Jacott et al., 2017; Thirkell et al., 2017). Whilst the host plant provides a fixed carbon (C) source for AMF, AMF transfer nutrients such as nitrogen $(\mathrm{N})$ and phosphorus $(\mathrm{P})$ to the plant (Hodge et al., 2001; Smith et al., 2009; Hodge and Fitter, 2010; Karasawa et al., 2012). AMF colonization affects multitrophic interactions between above- and below-ground herbivores (Yang et al., 2014) and may also enhance the uptake of silicon ( $\mathrm{Si}$ ), which can alleviate the impact of both biotic and abiotic stress (Dias et al., 2014; Garg and Bhandari, 2016; Frew et al., 2017).

The bottom-up effect of below-ground AMF on the performance of above-ground herbivores such as aphids can range from positive to negative (Gange and West, 1994; Wurst et al., 2004; Ueda et al., 2013; Simon et al., 2017; Wilkinson et al., 2019). These impacts on aphid performance likely occur because of alterations to plant defense and nutrition due to the AMF symbiosis (Wurst et al., 2004; Meir and Hunter, 2018b) and can depend on the level of AMF colonization of the host plant (Tomczak and Müller, 2017; Maurya et al., 2018; Meir and Hunter, 2018a). In turn, aphids may impose top-down effects on AMF colonization via the host plant (Babikova et al., 2014; Meir and Hunter, 2018a). Top-down and bottom-up effects can therefore modulate the outcome of each other, potentially resulting in above-below-ground multitrophic feedback loops (Meir and Hunter, 2018a). Thus, if aphids influence AMF colonization this could impact how AMF affect plant nutrient uptake and tolerance to abiotic stress in multitrophic systems. The AMF extraradical mycelium (ERM) phase is of also of key importance for interactions between plants and other rhizosphere organisms (Perotto and Bonfante, 1997; Jones et al., 2004; Hodge and Fitter, 2013) and can be directly related to AMF derived plant nutrient acquisition (Hodge et al., 2001; Barrett et al., 2011). Additionally, the ERM can be involved in plant defense, carrying signals of aphid attack to neighboring plants connected via ERM underground networks (Babikova et al., 2013). Elucidating how intra- and extraradical structures of AMF respond to top down effects is therefore important in understanding their potential for use in complex agro-ecosystems. However, current knowledge of how AMF respond to aphids sharing the same host plant is limited to the impact on AMF colonization (Babikova et al., 2014; Vannette and Hunter, 2014; Maurya et al., 2018; Meir and Hunter, 2018a).

The identity of the taxa within the AMF community colonizing the host plant can be important in determining the nutrient uptake or defense benefit gained from the symbiosis. In small, artificially selected AMF communities, AMF species identity determines the level of protection the AMF provides for the host plant against biotic stressors (Pozo et al., 2002; Sikes et al., 2009; Malik et al., 2016), and certain AMF species may deliver more or less nutrients to their host plant (Jansa et al., 2008; Leigh et al., 2009; Thirkell et al., 2016). Similarly, soil community transfer experiments suggests the AMF community structure can also be important in determining nutrient acquisition and plant growth responses (Hodge and Fitter, 2013; Williams et al., 2014; Manoharan et al., 2017;
Jiang et al., 2018). Large vertebrate grazing can affect AMF communities (Ba et al., 2012; Guo et al., 2016), and insect herbivory can alter below-ground ectomycorrhizal (Gehring and Bennett, 2009), non-mycorrhizal fungi (Kostenko et al., 2012) and rhizosphere bacterial community characteristics (Kong et al., 2016), but the impact of arthropod herbivory on AMF communities is currently unknown.

The impact of herbivory on AMF structures is variable (Barto and Rillig, 2010), and phloem feeding aphids can increase or decrease the intraradical AMF colonization of their host plant (Babikova et al., 2014; Meir and Hunter, 2018a). The C limitation hypothesis proposes that aboveground removal of fixed $\mathrm{C}$ by herbivory will result in less $\mathrm{C}$ available below-ground (Wallace, 1987), although the subsequent allocation of this limited amount of $\mathrm{C}$ between roots and AMF contained within roots is unknown. The reduced $\mathrm{C}$ availability might result in changes to the AMF community because only a limited number of AMF species can be supported and thus the number and relative abundance of less competitive species might be reduced (Gange, 2007; Ba et al., 2012). Alternatively, low levels of herbivory could lead to more $\mathrm{C}$ allocated below-ground in an attempt for the plant to take up more nutrients for regrowth (Wamberg et al., 2003), which could increase fungal diversity (Ba et al., 2012). There are also examples of herbivory affecting the composition of ectomycorrhizal communities rather than species richness, and thus altering the beta diversity of communities, making communities more distinct (Gehring and Bennett, 2009).

Arbuscular mycorrhizal fungi communities in conventionally managed agricultural systems are often distinct from AMF communities in other settings and often have low diversity due to tillage, chemical fertilizer, pesticide and fungicide regimes (Jansa et al., 2002; Gosling et al., 2006; Wetzel et al., 2014; Hartmann et al., 2015; Manoharan et al., 2017). We selected a conventionally managed system to investigate agriculturally relevant AMF communities that are tolerant to such practices. Apart from AMF, other fungi also associate with plant roots, including other endophytic mutualists (Murphy et al., 2015; Lugtenberg et al., 2016). As some of these other fungi and their community composition can influence aphid performance (Hartley and Gange, 2009; Battaglia et al., 2013; Kos et al., 2015), the AMF community must be placed in the context of any changes in the wider fungal community.

Here, we investigate the impact of aphids on the belowground fungal community with a focus on AMF given their key role as ecosystem engineers. Specifically, we tested the following hypotheses: (1) As aphids will depress plant growth and nutrient status, the AMF will benefit less from the association with the plant, and consequently AMF structures, both internal and external to the root, will be reduced. (2) Aphids will cause a reduction in both the alpha diversity and evenness of the soil communities, which results in a distinct soil fungal community composition (increased beta diversity). 


\section{MATERIALS AND METHODS}

\section{Site Selection}

Spring barley (Hordeum vulgare L., cultivar: Planet) was drilled into silty clay loam over chalk (Towthorpe, North Yorkshire, SE 91086 62387, GPS: 54.049412, - 0.610267, elevation above sea level: $100 \mathrm{~m}$ ) on March 15th, 2017. Average soil characteristics of the whole field were sampled on May 12th, 2017 and analyzed by NRM Laboratories (Berkshire, United Kingdom; Table 1). The field had been conventionally cropped with wheat and oats for the previous 5 years and was treated with conventional agrochemical inputs throughout the duration of this study (Table 1).

\section{Aphid Treatments}

On the April 21st, 2017, lidless and bottomless PVC boxes $(40 \mathrm{~cm} \times 40 \mathrm{~cm} \times 25 \mathrm{~cm})$ were inserted $2-3 \mathrm{~cm}$ below the surface of the soil around sections of developing three leaf stage seedlings, averaging $26 \pm 1.7 \mathrm{SE}$ plants per box. This shallow insertion, so as not to disturb plant roots, allowed an aphid impermeable seal to form between the soil and a cage structure. The interior of each box thus formed an experimental "plot." Experimental plots were assigned to "+Aphid" or "-Aphid" treatments and arranged in a randomized block design. As the site lay on a North Western slope, plots were set out in two rows perpendicular to the slope, in a North East direction. The location of the plots in the North East and North West direction were coded as the NE and NW coordinate (respectively) of each plot within the field site. This attempted to account for any locational environmental gradients within the site, and are referred to as the NE and NW plot location hereafter (Figure 1).

One week later (April 28th, 2017) cages were constructed to cover all plots. The frames of the cage consisted of wooden posts inserted $20 \mathrm{~cm}$ into the soil and were attached to the interior of the PVC box. The cage extended $90 \mathrm{~cm}$ above the soil and was covered with polypropylene horticultural fleece (Figure 2), which intercepted c. 14\% of the photosynthetically active radiation. English grain aphids (Sitobion avenae) (a single genotype, originally supplied by Koppert, Holland) were cultured on barley plants (cultivar Quench) at $20^{\circ} \mathrm{C}$. From these cultures, ten 4 th instar adults were taken at random and added to each +Aphid plot. All experimental plots (including - Aphid) were sealed with cages. S. avenae populations usually peak in the late summer months (Blackman and Eastop, 2000), however, aphids and cages were added to the crop in the current study earlier than this to stop the natural ingress of aphids into the plots. Initially, eight replicates of each treatment were set up, although one +Aphid replicate was discarded during the study due to damage to the cage caused by high wind speeds and so $N=8$ for - Aphid treatments and $N=7$ for + Aphid treatments. Cages remained over all treatments for the duration of the experiment, and may have reduced direct contact of some of the agrochemical inputs (see Table 1) with the plots after this date.

\section{Harvest}

Plots were harvested on the June 13th, 2017, 46 days post-aphid addition. The number of aphids on five tillers chosen at random within each plot were recorded, and plots were dug out to $20 \mathrm{~cm}$ soil depth before storage at $4^{\circ} \mathrm{C}$ overnight. Three soil cores at each plot location were taken with a $2 \mathrm{~cm}$ diameter cheese corer between 20 and $30 \mathrm{~cm}$ soil depth. These technical replicates were processed separately to assess for the fungal hyphal length density (HLD) from each core (Hodge, 2001) but then the resulting data was pooled to create a biological replicate. After storage, the aphids were washed from any above-ground material and plant roots were separated from the soil and washed whilst still attached to the above-ground biomass. Only those roots visibly attached to a plant were stored at $-20^{\circ} \mathrm{C}$ for DNA extraction or in $40 \%$ ethanol for the staining of fungal structures. The above-ground plant material was oven dried at $70^{\circ} \mathrm{C}$ for at least $96 \mathrm{~h}$ and the total number of plants, tillers and fertile tillers were recorded. The above-ground plant material for each plot was separated into a combined stem and leaf fraction (henceforth referred to as stem material) as well as a separate grain fraction. It should be noted that due to the size of the stem and leaf material, the stem and leaf fraction was weighed to the nearest gram. These fractions were homogenized in a kitchen blender (Igenix ig 8330, Ipswich, United Kingdom) before ball milling to a fine powder (Retsch MM400, Retsch GmbH, Haan, Germany). The resulting material was then analyzed for $\mathrm{C}$ and $\mathrm{N}$ ratios via a Elementar Vario El Cube (Elementar UK, Ltd., Stockport, United Kingdom) and pelleted for X-ray fluorescence (XRF) analysis (Thermo Fisher Scientific ${ }^{\mathrm{TM}}$ portable X-ray fluorescence analyzer) to determine $\mathrm{P}$ and Si concentrations as described by Reidinger et al. (2012).

The roots stored in $40 \%$ ethanol were stained for fungal structures via the acetic acid-ink staining method (Vierheilig et al., 1998), modified as in Wilkinson et al. (2019). Structures were assessed under a Nikon 50i eclipse microscope (Nikon UK Ltd., Surrey, United Kingdom) under 200 X magnification. As fungi other than AMF colonize plant roots in natural systems, a method that calculates both the most conservative estimation of AMF root length colonization (RLC) (RLC min) and least conservative (RLC max) was employed (Brundrett et al., 1994).

\section{DNA Extraction, PCRs, and Sequencing}

Frozen root material was lyophilized for $36 \mathrm{~h}$ and ball milled to a fine powder. The DNA was extracted from this material using a DNeasy PowerPlant Pro Kit (QIAGEN N.V, Venlo, Netherlands) according to the manufacturer's instructions with the exception that, in order to increase the DNA yield, the DNA solution was eluted twice through the membrane in the final step. DNA concentrations were assessed (NanoDrop ${ }^{\text {TM }}$ 8000 Spectrophotometer Thermo Fisher Scientific) and diluted to $20 \mathrm{ng}^{\mathrm{Cl}} \mathrm{l}^{-1}$ before the PCR analysis.

Two regions (amplicons) of fungal ribosomal DNA were amplified via PCR (Table 2); an amplicon that captures the diversity of the entire fungal community (total fungi), and an amplicon that captures AMF specific diversity at a higher resolution and species coverage (AMF specific). After initial amplification via primary PCRs, secondary PCRs attached illumina sequencing barcodes. For all PCRs the reaction consisted of $0.5 \mu \mathrm{l} \mathrm{DNA}, 0.1 \mu \mathrm{l}$ of forward and reverse primers $(20 \mathrm{mM})$ and $12.5 \mu \mathrm{l}$ BioMix Red (Bioline, London, United Kingdom) made up to $25 \mu \mathrm{l}$ reaction volume with molecular grade $\mathrm{dH}_{2} \mathrm{O}$. 
TABLE 1 | Fieldsite soil chemical analyses and agrochemical inputs used throughout the study.

Soil analyses (sampled May 12, 2017)

$\mathrm{P}$ (Olsen's)

$\mathrm{K}$ (Ammonium nitrate extracted)

Mg (Ammonium nitrate extracted)

$\mathrm{pH}$

Organic matter \% (Loss on ignition)

Agrochemical inputs

Herbicides

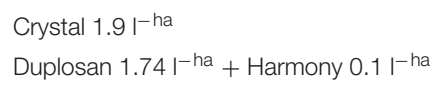

Gal-Gone $0.5 \mathrm{I}^{- \text {ha }}$

Axial $0.3 \mathrm{I}^{\text {-ha }}+$ Agidor (Adjuvant) $0.1 \mathrm{I}^{\text {-ha }}$

Fungicides

\author{
Siltra Xpro $0.41^{- \text {ha }}$ \\ Chlorothalonil $1.0 \mathrm{I}^{- \text {ha }}+$ Siltra Xpro $0.4 \mathrm{I}^{\text {-ha }}$
}

Plant Growth Regulators

Terpal $0.581^{- \text {ha }}$

Fertilizer

$$
\begin{aligned}
& 182 \mathrm{mg} \mathrm{l}^{-1} \\
& 274 \mathrm{mg} \mathrm{I}^{-1} \\
& 47 \mathrm{mg} \mathrm{l}^{-1} \\
& 7.4 \\
& 6.8
\end{aligned}
$$

Active ingredient concentration in concentrated product

Date of input

$60 \mathrm{~g} \mathrm{I}^{-1}$ flufenacet, $300 \mathrm{~g} \mathrm{I}^{-1} \mathrm{gl}$ pendimethalin

$310 \mathrm{~g} \mathrm{I}^{-1}$ Dichlorprop-P acid, $160 \mathrm{~g} \mathrm{I}^{-1}$ MCPA acid, $130 \mathrm{~g}$

$\mathrm{I}^{-1}$ Mecoprop-P acid $40 \mathrm{~g} \mathrm{~kg}^{-1}$ metsulfuron-methyl, $400 \mathrm{~g}$

$\mathrm{kg}^{-1}$ thifensulfuron-methyl

$200 \mathrm{~g} \mathrm{I}^{-1}$ fluroxypy

$100 \mathrm{~g} \mathrm{I}^{-1}$ pinoxaden $47 \% \mathrm{w} / \mathrm{w}$ methylated rapeseed oil

$60 \mathrm{~g} \mathrm{I}^{-1}$ bixafen, $200 \mathrm{~g} \mathrm{I}^{-1}$ prothioconazole and

$\mathrm{N}, \mathrm{N}$-Dimethyldecanamide

$395 \mathrm{~g} \mathrm{I}^{-1}$ mepiquat chloride, $155 \mathrm{~g} \mathrm{I}^{-1}$

2-chloroethylphosphonic acid
June 03, 2017

June 04, 2017

May 25, 2017

June 12, 2017

June 03, 2017

March 15, 2017

May 25, 2017

March 16, 2017

March 31, 2017

April 20, 2017
PCRs were carried out using a T100 ${ }^{\mathrm{TM}}$ Thermal Cycler (BioRAD, Hercules, CA, United States). The PCR products of the secondary PCRs were purified using a QIAquick PCR Purification Kit (Qiagen) and the purified concentrations were measured using a Qubit ${ }^{\circledR}$ 3.0 fluorometer (Thermo Fisher Scientific ${ }^{\mathrm{TM}}$, Waltham, MA, United States). To mix the products of the two amplicons at equimolar concentrations to reduce sequencing depth bias during simultaneous DNA sequencing, these products were lyophilized overnight and re-suspended in molecular grade $\mathrm{H}_{2} \mathrm{O}$ to achieve desired concentrations. Quality control and library preparation was carried out by the University of York Bioscience Technology Facility, and the resulting samples were sequenced using an illumina MiSeq system (illumina, San Diego, CA, United States) at $2 \sim 300$ bp: Briefly, unique barcode sequences (Nextera XT index primers, illumina) were added onto amplicons tagged with illumina adapter sequences via

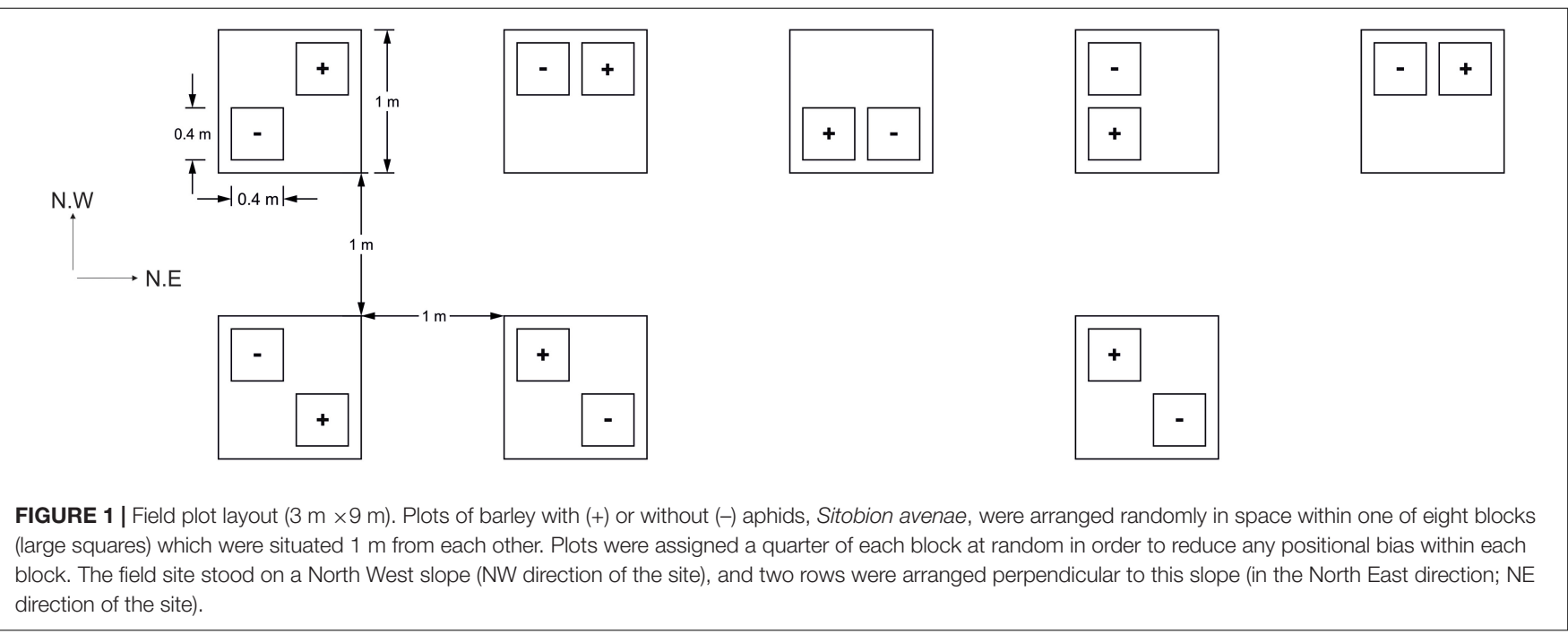



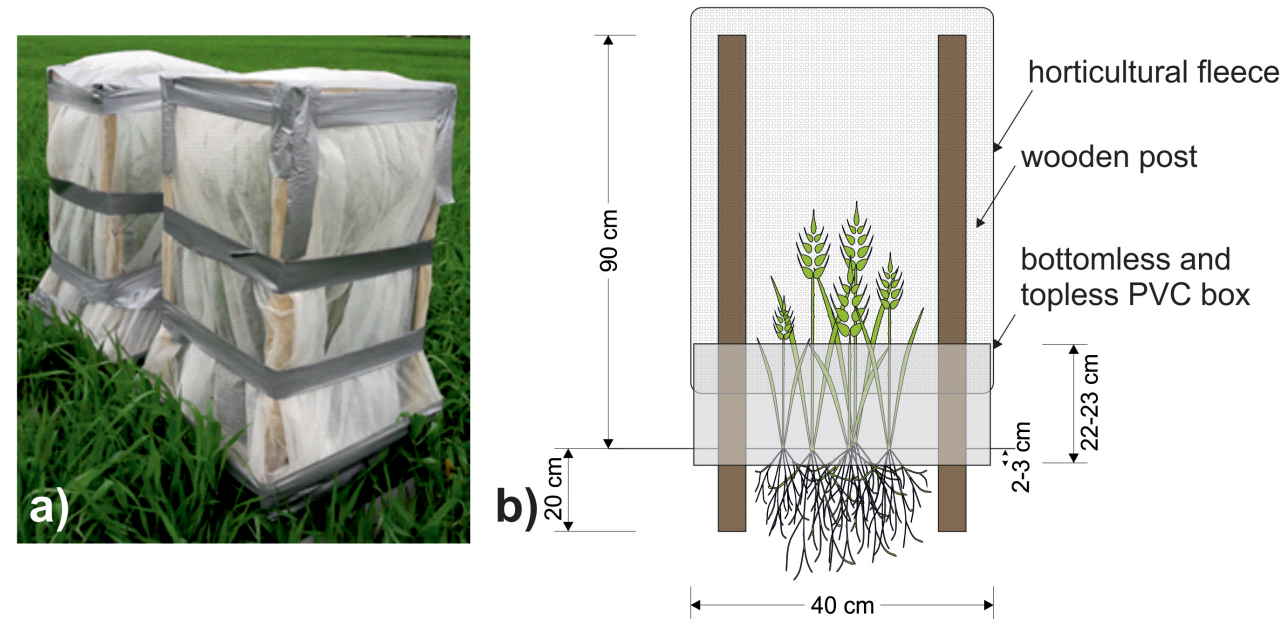

FIGURE 2 | (a) Photograph of a pair of completed aphid cages covering plots taken on 17th May 2017. (b) Schematic of cage design used to prevent aphid movement between the plots. Wooden posts reaching $90 \mathrm{~cm}$ high were inserted $20 \mathrm{~cm}$ into the ground to support a cage of polypropylene horticultural fleece sealed to a $40 \mathrm{~cm} \times 40 \mathrm{~cm}$ PVC box reaching $22-23 \mathrm{~cm}$ above ground.

PCR. Amplicons were then purified and pooled at equimolar ratios and then diluted and denatured. Samples were spiked with PhiX library spikes (illumina) for added sequence variety to enhance the distinguishing of fluorescent signals of clusters during sequencing. Samples were run using the MiSeq 600 cycle kit (illumina).

\section{Bioinformatic Analysis}

The raw forward and reverse reads were merged together resulting in a total of $c$. 1.5 million reads which were processed using QIIME2 ${ }^{1}$ (Caporaso et al., 2010). Reads were stripped of their primer and barcoding sequences and untrimmed reads were discarded $(0.9 \%)$. Read quality of the merged reads were estimated using eestats 2 and reads from AMF specific amplicons were truncated to $270 \mathrm{bp}$ from the front end due to estimated sequence quality drop off at this point, whilst total fungal amplicons were not truncated. Reads were then dereplicated and clustered into operational taxonomic units (OTUs) using Usearch10 (Edgar, 2010) with 97\% similarity. The resulting 517

${ }^{1}$ https://qiime2.org total fungi amplicon OTUs were BLASTed against the UNITE ITS (Kõljalg et al., 2013) database and eight non-fungal OTUs were removed, resulting in 509 total fungi OTUs, with the total read number per sample ranging from 53,333 to 129,338. Samples were normalized to 70,000 reads per sample using Usearch10's "norm" function. Identical virtual taxon accessions according to the UNITE database were merged together yielding the 155 total fungi amplicon OTUs used in subsequent analysis.

A total of 27 OTUs were identified for the AMF specific amplicon. These were BLASTed against the maarjAM database (Öpik et al., 2010) accessed on 13th June 2018 and five OTUs with less than $96 \%$ coverage or similarity to taxa in the database were discarded. This resulted in a total read number from 12,035 to 21,706 per sample. Reads per sample were normalized to 16,500. AMF virtual taxonomic (VT) identities were assigned to the OTUs according to the greatest BLAST coverage and similarity; where OTUs could not be assigned to a single VT, VTs were labeled as unassigned. A phylogenetic tree of the sequences was built to identify identical VT accessions. Identical VTs were merged together resulting in 15 OTUs used in subsequent analysis.

TABLE 2 | Primer sets and PCR conditions used in nested PCRs for "total fungi" and "AMF specific" amplicon sequencing.

\begin{tabular}{|c|c|c|c|c|}
\hline Amplicon & & Primer pairs & Cycling conditions & DNA used in reaction \\
\hline & Primary PCR & $\begin{array}{l}\text { ITS1F (Gardes and Bruns, 1993) to } \\
\text { ITS4 (White et al., 1990) }\end{array}$ & $\begin{array}{l}5 \text { min @ 95 } 5^{\circ} \mathrm{C} ; 35 \text { cycles }\left(30 \mathrm{~s} @ 94^{\circ} \mathrm{C}, 45 \mathrm{~s} @\right. \\
\left.55^{\circ} \mathrm{C}, 90 \mathrm{~s} @ 72^{\circ} \mathrm{C}\right) ; 10 \mathrm{~min} @ 72^{\circ} \mathrm{C} .\end{array}$ & 10 ng extracted DNA \\
\hline & $\begin{array}{l}\text { Secondary PCR (illumina } \\
\text { tagged primers) }\end{array}$ & $\begin{array}{l}\text { GITS7 (Ihrmark et al., 2012) to ITS4 } \\
\text { (White et al., 1990) }\end{array}$ & $\begin{array}{l}5 \min @ 95^{\circ} \mathrm{C} ; 30 \text { cycles }\left(30 \mathrm{~s} @ 94^{\circ} \mathrm{C}, 45 \mathrm{~s} @\right. \\
\left.55^{\circ} \mathrm{C}, 90 \mathrm{~s} @ 72^{\circ} \mathrm{C}\right) ; 5 \min @ 72^{\circ} \mathrm{C} .\end{array}$ & $\begin{array}{l}\text { Total fungi primary PCR } \\
\text { product (diluted 1:1000) }\end{array}$ \\
\hline \multicolumn{5}{|c|}{ AMF specific } \\
\hline & $\begin{array}{l}\text { Secondary PCR (illumina } \\
\text { tagged primers) }\end{array}$ & $\begin{array}{l}\text { WANDA (Dumbrell et al., 2011) to } \\
\text { AML2 (Lee et al., 2008) }\end{array}$ & $\begin{array}{l}5 \mathrm{~min} @ 95^{\circ} \mathrm{C} ; 30 \text { cycles }\left(30 \mathrm{~s} @ 94^{\circ} \mathrm{C}, 40 \mathrm{~s} @\right. \\
\left.59^{\circ} \mathrm{C}, 90 \mathrm{~s} @ 72^{\circ} \mathrm{C}\right), 10 \mathrm{~min} @ 72^{\circ} \mathrm{C} .\end{array}$ & $\begin{array}{l}\text { AMF specific primary PCR } \\
\text { product (undiluted) }\end{array}$ \\
\hline
\end{tabular}




\section{Statistical Analysis}

Alpha diversity metrics [OTU/VT richness, Shannon's Index (e), Peilou's Evenness and Simpson's Diversity] were calculated using Usearch10's (Edgar, 2010) alpha diversity command and all subsequent analyses were carried out in $\mathrm{R}$ version 3.3.2 (October 31, 2016) (R Core Team, 2016). To test the effect of the aphid treatment on AMF and total fungi alpha diversity metrics, AMF family relative abundance, and plant and AMF structures, aphid presence was used as an explanatory variable in a linear model, using the R packages "Ime4," "ImerTest," "Ismeans," and "car." Plot location, measured as the NE and NW distance of each plot from the NW corner of the field site, was used as a covariate (see Table 3). To identify fungal OTUs/VTs whose presence predicts aphid treatment we employed indicator species analysis using the "indicspecies" package. The identification and estimation of abundances of AMF is more accurate using the AMF specific amplicon (Berruti et al., 2017), thus total fungi OTUs corresponding to AMF taxa were excluded from the indicator species analysis of the total fungi amplicon. The effect of aphid presence on community composition between samples as measured via Bray-Curtis dissimilarity (Beta diversity) was analyzed using a PERMANOVA via the "Adonis" function in the "Vegan" $\mathrm{R}$ package. This was visualized via nonmetric multidimensional scaling (NMDS). Relationships between community composition and plant biomass and nutrition, and AMF structures as well as plot location were tested by applying the "envfit" function to the NMDS.

\section{RESULTS}

\section{Effect of Aphid Presence on Plant Nutrition and Biomass, and AMF Structures}

The mean number of aphids per tiller \pm SE in "+Aphid" plots was $24.9 \pm 8.2$, and ranged from between 1.8 and 75 , whilst no aphids were present on any tillers investigated for "Aphid" plots. Whilst the majority of plant biomass and nutrition, and AMF physiological traits were not influenced by aphid treatment (Table 3), aphid treatment significantly increased the stem N:P ratio by $5.4 \%$ (Table 3 ), and there was a near significant increase of $8.9 \%(P=0.052)$ of the grain $\mathrm{N}: \mathrm{P}$ ratio. Grain $\mathrm{P}$ concentration and N:P ratio was associated with the position of the plot in the NE direction of the site (Table 3). While aphid treatment did not significantly impact any AMF structures, there was a trend that the vesicle frequency almost doubled in the roots of plants hosting aphids $(P=0.097)$. The frequency of vesicles was associated with the position of the plot in the NW direction (Table 3).

\section{Effect of Aphid Presence on Total Fungal and AMF Communities in the Root}

Within the entire fungal community in plant roots across both aphid treatments, 153 "total fungi" OTUs were identified from nine fungal phyla and 2 OTUs that could not be assigned at the phylum level. The highest abundance of sequences were assigned to Ascomycota $(90.2 \%)$, followed by Basidiomycota (5.3\%), unclassified fungi (3.5\%), Glomeromycota (0.83\%), and Chytridiomycota $(0.08 \%)$. In contrast, sequences from Rozellomycota, Mortierellomycota, Entomophthoromycota, Mucoromycota, and Zoopagomycota contributed less than a combined $0.1 \%$ of sequence abundance. Within the AMF specific amplicon, 12 OTUs were assigned to VTs whilst three OTUs could not be assigned to a singular VT (see Supplementary Table S1). These VTs belonged to seven AMF families: Glomeraceae (6), Paraglomeraceae (1), Diversisporaceae (2), Ambisporaceae (1), Gigasporaceae (1), Archaeosporaceae (3), and Acaulosporaceae (1).

Aphid presence did not affect the species richness within the entire fungal community, but did increase its evenness (Table 4). Aphid presence also did not affect any AMF specific alpha diversity metrics. The Simpson's diversity of the AMF specific community was linked to plot location in the NE direction of the field site (Table 4).

Aphid presence had no effect on the relative abundance of AMF reads within the entire fungal community. Within the AMF specific amplicon the relative abundance of the Gigasporaceae family tended to increase when aphids were present (Table 5). The relative abundance of AMF reads within the entire fungal community, and the relative abundance of the Gigasporaceae and Ambisporaceae families present in the AMF specific community were associated with the location of the plot in the NE direction of the site (Table 6).

All but two AMF specific amplicon VTs were found in both aphid and no aphid treatments, however, the exceptions were not strong indicators of aphid presence or absence (Table 6). Several Ascomycota taxa were strong predictors of the absence of aphids for the total fungi amplicon, whilst a member of the family Cystobasidiaceae indicated aphid presence.

The total fungi amplicon community composition between plots, measured as Bray-Curtis dissimilarity (beta diversity) was not significantly affected by aphid presence (PERMANOVA: $\left.F_{1,13}=1.75, P=0.131\right)$. However, community composition correlated with plot location in the NE direction of the site $\left(R^{2}=0.46, P=0.031\right)$ and grain $\mathrm{P}$ concentration $\left(R^{2}=0.46\right.$, $P=0.021$; Figure 3).

The community composition of AMF specific VTs in the roots of barley plants between plots was not affected by the presence of aphids $\left(F_{1,13}=0.46, P=0.604\right)$. However, the environmental factors of stem $\mathrm{Si}$ concentration and location of the plots in the NE direction of the field site were significantly correlated with the community composition $\left(R^{2}=0.39, P=0.049\right.$ and $R^{2}=0.40$, $P=0.049$, respectively; Figure 4).

\section{DISCUSSION}

This study aimed to investigate the impact of aphids on soil fungi in a conventionally managed agricultural system. It was hypothesized that by supressing plant nutrition and growth, aphid feeding would lead to negative impacts on AMF structures and species richness, as well as the evenness 
TABLE 3 | Mean ( \pm SE) above-ground plant biomass and nutrient concentrations, and AMF structures of experimental barley plots treated with or without aphids, using the location of the plot in the NE and NW direction of the site as a model covariate.

\begin{tabular}{|c|c|c|c|c|c|c|c|c|}
\hline & \multirow[b]{3}{*}{-Aphid } & \multirow[b]{3}{*}{ +Aphid } & & & \multicolumn{4}{|c|}{ Plot location covariate } \\
\hline & & & \multicolumn{2}{|c|}{ Aphid presence } & \multicolumn{2}{|c|}{ NE } & \multicolumn{2}{|c|}{ NW } \\
\hline & & & $F_{1,11}$ & $P$ & $F_{1,11}$ & $P$ & $F_{1,11}$ & $P$ \\
\hline Plant No m-21. & $172.5 \pm 20$ & $156.9 \pm 11.3$ & 0.439 & 0.521 & 0.085 & 0.777 & 0.764 & 0.401 \\
\hline Fertile tiller $\mathrm{No} \mathrm{m}^{-2}$ & $301.9 \pm 29.4$ & $319.4 \pm 36.3$ & 0.164 & 0.693 & 0.353 & 0.565 & 0.647 & 0.438 \\
\hline Total tiller No m ${ }^{-2}$ & $446.3 \pm 28.1$ & $418.8 \pm 31.3$ & 0.440 & 0.521 & 1.99 & 0.186 & 0.460 & 0.512 \\
\hline Stem DW m². & $356 \pm 29.4$ & $356 \pm 21.9$ & 0.002 & 0.963 & 0.097 & 0.761 & 1.731 & 0.215 \\
\hline Plot grain DW m² & $68.1 \pm 8.6$ & $67.9 \pm 2.9$ & $<0.001$ & 0.982 & 0.244 & 0.631 & 0.024 & 0.880 \\
\hline Mean tiller DW & $0.95 \pm 0.06$ & $1.02 \pm 0.05$ & 0.985 & 0.342 & 1.706 & 0.218 & 0.767 & 0.399 \\
\hline Mean grain DW & $0.22 \pm 0.01$ & $0.23 \pm 0.03$ & 0.007 & 0.934 & 0.182 & 0.678 & 0.967 & 0.347 \\
\hline Stem $[P]^{3 .}$ & $2.46 \pm 0.10$ & $2.46 \pm 0.14$ & $<0.001$ & 0.996 & 0.030 & 0.865 & 0.040 & 0.845 \\
\hline Stem [N] & $18.16 \pm 0.71$ & $19.08 \pm 0.89$ & 0.664 & 0.432 & 0.139 & 0.716 & 0.035 & 0.855 \\
\hline Stem [Si] & $9.69 \pm 0.70$ & $8.57 \pm 0.48$ & 1.599 & 0.232 & 0.005 & 0.943 & 0.077 & 0.786 \\
\hline Stem [C] & $420.9 \pm 2.13$ & $420.1 \pm 2.16$ & 0.055 & 0.819 & 0.370 & 0.556 & $<0.001$ & 0.979 \\
\hline Stem C:N & $23.38 \pm 1.06$ & $22.28 \pm 0.97$ & 0.574 & 0.465 & 0.343 & 0.570 & 0.009 & 0.926 \\
\hline Stem N:P & $7.40 \pm 0.11$ & $7.80 \pm 0.18$ & 5.143 & 0.045 & 2.806 & 0.122 & 1.200 & 0.297 \\
\hline Grain [P] & $3.63 \pm 0.14$ & $3.49 \pm 0.10$ & 0.899 & 0.363 & 5.122 & 0.045 & 0.059 & 0.813 \\
\hline Grain [N] & $17.50 \pm 0.52$ & $18.38 \pm 0.43$ & 1.734 & 0.215 & 0.719 & 0.415 & 0.154 & 0.702 \\
\hline Grain [Si] & $10.30 \pm 0.55$ & $9.43 \pm 0.58$ & 1.239 & 0.289 & 0.443 & 0.519 & 0.031 & 0.864 \\
\hline Grain [C] & $418.7 \pm 1.89$ & $421.7 \pm 1.74$ & 1.324 & 0.274 & 0.194 & 0.668 & 0.025 & 0.876 \\
\hline Grain C:N & $24.05 \pm 0.72$ & $23.00 \pm 0.62$ & 1.194 & 0.298 & 0.442 & 0.520 & 0.102 & 0.756 \\
\hline Grain N:P & $4.85 \pm 0.21$ & $5.28 \pm 0.16$ & 4.736 & 0.052 & 10.591 & 0.008 & 0.376 & 0.552 \\
\hline RLC Min 4 . & $32.67 \pm 3.14$ & $33.48 \pm 3.06$ & 0.034 & 0.857 & 0.021 & 0.888 & 0.409 & 0.536 \\
\hline RLC Max ${ }^{4}$ & $47.45 \pm 3.71$ & $49.91 \pm 3.91$ & 0.284 & 0.605 & 0.149 & 0.707 & 0.715 & 0.416 \\
\hline HLD $^{5 .}$ & $0.32 \pm 0.03$ & $0.34 \pm 0.04$ & 0.315 & 0.586 & 0.026 & 0.875 & 0.001 & 0.973 \\
\hline Arbuscule & $29.20 \pm 2.57$ & $29.77 \pm 3.56$ & 0.019 & 0.893 & 0.139 & 0.716 & 1.078 & 0.322 \\
\hline Vesicle ${ }^{4}$ & $2.75 \pm 1.03$ & $5.29 \pm 1.78$ & 3.296 & 0.097 & 0.021 & 0.888 & 11.606 & 0.006 \\
\hline
\end{tabular}

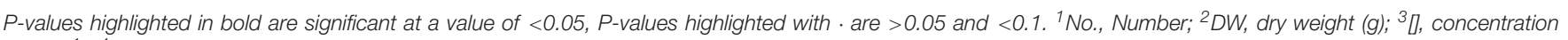

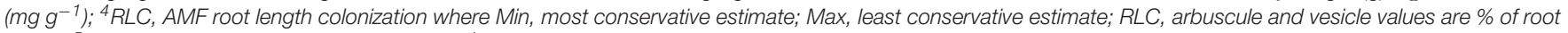
length; ${ }^{5} \mathrm{HLD}$, hyphal length density ( $m$ hyphae $g^{-1}$ soil).

TABLE 4 | Mean ( \pm SE) Alpha diversity metrics for "total fungi" amplicon OTUs, and "AMF specific" amplicon VTs from barley plots without or without the presence of aphids, using the location of the plot in the NE and NW direction of the site as a model covariate.

\begin{tabular}{|c|c|c|c|c|c|c|c|c|}
\hline & \multirow[b]{3}{*}{-Aphid } & \multirow[b]{3}{*}{ +Aphid } & & & \multicolumn{4}{|c|}{ Plot location covariate } \\
\hline & & & \multicolumn{2}{|c|}{ Aphid presence } & \multicolumn{2}{|c|}{ NE } & \multicolumn{2}{|c|}{ NW } \\
\hline & & & $F_{1,11}$ & $P$ & $F_{1,11}$ & $P$ & $F_{1,11}$ & $P$ \\
\hline \multicolumn{9}{|l|}{ Total fungi } \\
\hline OTU richness & $92.6 \pm 2.5$ & $89.4 \pm 2.3$ & 0.889 & 0.366 & 0.281 & 0.607 & 0.087 & 0.774 \\
\hline Shannon's index & $2.54 \pm 0.09$ & $2.75 \pm 0.06$ & 3.725 & 0.080 & 0.008 & 0.932 & 0.170 & 0.688 \\
\hline Peilou's evenness & $0.56 \pm 0.02$ & $0.61 \pm 0.01$ & 5.090 & 0.045 & $<0.001$ & 0.977 & 0.260 & 0.620 \\
\hline Simpson's diversity & $0.15 \pm 0.02$ & $0.11 \pm 0.01$ & 3.059 & 0.108 & 0.527 & 0.483 & 0.377 & 0.551 \\
\hline \multicolumn{9}{|l|}{ AMF } \\
\hline VT richness & $11.3 \pm 0.3$ & $11.1 \pm 0.5$ & 0.033 & 0.859 & 0.004 & 0.953 & 0.105 & 0.752 \\
\hline Shannon's index & $1.17 \pm 0.11$ & $1.20 \pm 0.09$ & 0.047 & 0.833 & 2.646 & 0.132 & 0.264 & 0.618 \\
\hline Peilou's evenness & $0.49 \pm 0.04$ & $0.51 \pm 0.04$ & 0.075 & 0.790 & 3.018 & 0.110 & 0.429 & 0.526 \\
\hline Simpson's diversity & $0.47 \pm 0.05$ & $0.44 \pm 0.05$ & 0.226 & 0.644 & 6.207 & 0.030 & 0.176 & 0.683 \\
\hline
\end{tabular}

Richness: number of OTUSNTS. P-values highlighted in bold are significant at a value of $<0.05$, P-values highlighted with · are $>0.05$ and $<0.1$. 
TABLE 5 | Mean ( \pm SE) relative abundances of the AMF sequences within the "total fungi" amplicon, and of AMF family sequences from the "AMF specific amplicon," from experimental barley plots infested with or without aphids, using the location of the plot in the NE and NW direction of the site as a model covariate.

\begin{tabular}{|c|c|c|c|c|c|c|c|c|}
\hline \multirow[b]{3}{*}{ Relative abundance } & \multirow[b]{3}{*}{-Aphid } & \multirow[b]{3}{*}{ +Aphid } & & & \multicolumn{4}{|c|}{ Plot location covariate } \\
\hline & & & \multicolumn{2}{|c|}{ Aphid presence } & \multicolumn{2}{|c|}{ NE } & \multicolumn{2}{|l|}{ NW } \\
\hline & & & $F_{1,11}$ & $P$ & $F_{1,11}$ & $P$ & $F_{1,11}$ & $P$ \\
\hline AMF & $0.53 \pm 0.29$ & $1.18 \pm 0.63$ & 1.450 & 0.254 & 5.447 & 0.040 & 0.145 & 0.710 \\
\hline Acaulosporaceae & $0.02 \pm 0.02$ & 0 & - & - & - & - & - & - \\
\hline Ambisporaceae & $3.21 \pm 0.79$ & $2.92 \pm 0.71$ & 0.123 & 0.732 & 8.111 & 0.016 & 0.036 & 0.854 \\
\hline Archaeosporaceae & $1.23 \pm 0.41$ & $0.63 \pm 0.19$ & 1.828 & 0.204 & 0.056 & 0.817 & 1.848 & 0.201 \\
\hline Diversisporaceae & $3.72 \pm 0.68$ & $5.68 \pm 2.52$ & 0.767 & 0.400 & 2.241 & 0.163 & 0.198 & 0.665 \\
\hline Gigasporaceae & $0.77 \pm 0.20$ & $1.48 \pm 0.52$ & 4.106 & 0.067 & 13.560 & 0.004 & 0.553 & 0.473 \\
\hline Glomeraceae & $85.44 \pm 2.18$ & $83.43 \pm 2.30$ & 0.420 & 0.530 & 0.778 & 0.397 & $<0.001$ & 0.990 \\
\hline Paraglomeraceae & $5.62 \pm 1.32$ & $5.86 \pm 1.54$ & 0.016 & 0.900 & 0.658 & 0.434 & 1.119 & 0.313 \\
\hline
\end{tabular}

P-values highlighted in bold are significant at a value of $<0.05$, P-values highlighted with $\cdot$ are $>0.05$ and $<0.1$.

of the AMF and other fungi communities, measured here through analysis of an AMF specific amplicon and another less precise, but wider encompassing amplicon (total fungi). It was also proposed that the effects of aphids would impact the compositions of these communities (Gehring and Bennett, 2009), and the relative abundance of AMF taxa within them. In fact, aphid presence had less of an impact on AMF community structure than the location of the host plant in the field, although there was a trend of the abundance of AMF vesicles, and the abundance of the Gigasporaceae family to increase when aphids fed on the host plant. Within the total fungi community, the relative abundance of AMF was also affected by location rather than aphid presence. However, aphid presence increased evenness across the total fungi community.

TABLE 6 | Indicator species analysis of AMF specific amplicon VTs and total fungi amplicon OTUs as indicators of untreated or aphid treated barley plots.

\begin{tabular}{|c|c|c|c|c|}
\hline \multirow[t]{2}{*}{ OTU/VT } & \multicolumn{2}{|c|}{ VT/OTU present within treatment } & \multirow[t]{2}{*}{ IndVal } & \multirow[t]{2}{*}{$P$} \\
\hline & -Aphid & +Aphid & & \\
\hline \multicolumn{5}{|l|}{ AMF specific } \\
\hline $\begin{array}{l}\text { Acaulospora } \\
\text { VTX00030 }\end{array}$ & $\checkmark$ & $x$ & 0.35 & 1.000 \\
\hline $\begin{array}{l}\text { Glomus } \\
\text { VTX00199 }\end{array}$ & $x$ & $\checkmark$ & 0.49 & 0.349 \\
\hline \multicolumn{5}{|l|}{ Total fungi } \\
\hline $\begin{array}{l}\text { Ascomycota; } \\
\text { Pseudeurotiaceae }\end{array}$ & $\checkmark$ & $x$ & 0.92 & 0.006 \\
\hline $\begin{array}{l}\text { Ascomycota; } \\
\text { Helotiales }\end{array}$ & $\checkmark$ & $x$ & 0.88 & 0.046 \\
\hline $\begin{array}{l}\text { Ascomycota; } \\
\text { Halosphaeriaceae }\end{array}$ & $\checkmark$ & $x$ & 0.87 & 0.032 \\
\hline $\begin{array}{l}\text { Basidiomycota; } \\
\text { Cystobasidiaceae }\end{array}$ & $\times$ & $\checkmark$ & 0.81 & 0.029 \\
\hline
\end{tabular}

Only total fungi amplicon OTUs which significantly indicate (bold) the aphid treatments are shown. $\checkmark$ indicates the presence of the taxon, while $\times$ indicates its absence.

\section{Effects of Aphids on the Plant Biomass and Nutrition, and AMF Structures}

Contrary to our hypothesis, S. avenae had little effect on the above-ground nutrition of barley in the field, although aphid presence tended to increase the above-ground plant $\mathrm{N}: \mathrm{P}$ ratio (Table 3), possibly due to nutrient re-allocation caused by aphid feeding (Sandstrom et al., 2000; Thompson and Goggin, 2006; Nowak and Komor, 2010), or differences between the requirement for $\mathrm{N}$ and $\mathrm{P}$ by aphids (Tao and Hunter, 2012). Moreover, aphid presence did not reduce above-ground biomass in the present study. Since the aphids used in this experiment were cultured under controlled conditions it is likely that as the aphids did not vector any plant viruses that are a major contributor to aphid related yield loss in cereals (McKirdy et al., 2002). While it is possible that the agro-chemical inputs of fungicides, herbicides and plant growth regulators in this conventionally managed system may have influenced aphid development, the total number of aphids per tiller, and thus, estimated in each "+ Aphid" plot, remained high. However, the aphid population in the current experiment was launched at an earlier date than in non-controlled systems (Blackman and Eastop, 2000) which may have also influenced the results. AMF colonization of barley roots was high compared to that measured in field studies previously (Boyetchko and Tewari, 1995), and in certain glasshouse studies (Grace et al., 2009). Thus, while we originally hypothesized that aphids would have a negative impact on above-ground plant biomass and nutrition which in turn, would reduce both the internal and external phases of the AMF, no negative impact occurred. This may explain why both AMF RLC and hyphal length density were not affected by the presence of aphids in this study. However, there was a trend for aphids to increase the proportion of vesicles in plant roots. Mechanical defoliation has also been shown to influence the proportion of vesicles in plant roots when grown with a native AMF soil community (Garcia and Mendoza, 2012). As vesicles are lipid storage organs in AMF, and AMF derive lipids from the host plant (Keymer and Gutjahr, 2018), this might suggest that more fixed $C$ is available to the AMF via the plant under aphid herbivory. 


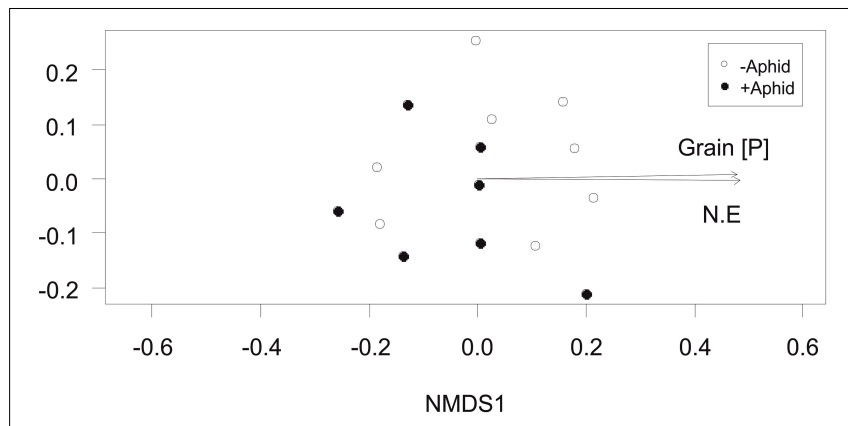

FIGURE 3 | Total fungi community composition: Non-Metric Multidimensional Scaling (NMDS) of total fungi community distribution based on Bray-Curtis dissimilarity (stress $=0.158$ ) obtained from the abundance of "total fungi amplicon" OTUs under "+Aphid," or "-Aphid" treatments. Total fungi community composition was significantly associated with the grain $\mathrm{P}$ concentration $\left(\mathrm{mg} \mathrm{g}^{-1}\right)$ in the plots (Grain [P]) and the location of the plot in the NE direction of the site (NE).

\begin{tabular}{l} 
FIGURE 4 | Arbuscular mycorrhizal fungi specific community composition: \\
Non-Metric Multidimensional Scaling (NMDS) of the AMF community \\
distribution based on Bray-Curtis dissimilarity (stress = 0.154) obtained from \\
the abundance of "AMF specific amplicon" VTs under "+Aphid" or "-Aphid" \\
treatments. AMF specific community composition was significantly associated \\
with the barley stem silicon Si (mg g-1) concentration in the plots (Stem [Si]), \\
and the location of the plot in the NE direction of the site (NE coordinate). \\
\hline
\end{tabular}

Alternatively, AMF vesicle numbers may have increased in a response to less $\mathrm{C}$ flow from the plant in order to aid survival under stressed conditions, similar to the AMF response observed in cool conditions (Hawkes et al., 2008), It is also possible that the frequency of AMF with a propensity to form more vesicles occurred within the Glomeracea community. However, the tendency for aphid presence to increase the relative abundance of the AMF family Gigasporaceae, which do not develop vesicles (Smith and Read, 2008), suggests that this explanation is less likely.

\section{Effects of Aphids on AMF and Total Fungal Communities}

The second hypothesis proposed that the effects of aphid feeding on the host plant would reduce AMF and total fungal species richness and evenness. The low richness of AMF species identified in the current study is similar to that documented in other conventionally managed barley monoculture systems
(Manoharan et al., 2017), and as the read depth achieved for the AMF specific amplicon is sufficient to capture AMF diversity (Vasar et al., 2017), it can be assumed that this is an accurate representation. The number of species of AMF were not impacted by aphid presence perhaps as there was no effect of aphid presence on above-ground plant biomass; however, this is similar to the lack of an effect of arthropod feeding on pinyon pine associated ectomycorrhizal communities (Gehring and Bennett, 2009). This was also reflected in the number of species in the entire fungal community in the current study. Moreover, and counter to expectations, aphid presence increased the evenness of the entire fungal community in the present study. Nutrient flows below-ground were not measured in the current study, but aphids can affect below-ground respiration depending on plant growth stage, potentially due to alterations in $\mathrm{C}$ availability to soil microbes (Vestergård et al., 2004). Aphids can also alter the profiles of compounds, released from plant roots (Hoysted et al., 2018) and can also change the profiles of sugars found in AMF hyphae sharing the same host plant (Cabral et al., 2018). Moreover, aphids excrete honeydew as a result of their $\mathrm{C}$ rich diet of phloem sap which can be utilized as a $C$ source by soil microbiota, thus shaping community structure and biomass (Katayama et al., 2014; Milcu et al., 2015). As more C sources become available in the root, it is possible that niches may enlarge allowing less competitive fungi to compete, reducing the dominance of abundant taxa. However, it should be noted that aphid induced alterations to soil organisms can occur independently of honeydew C inputs (Sinka et al., 2009), and that soil microbes can be influenced by aphid induced changes to plant root exudates in systems where honeydew does not reach the microbe (Kim et al., 2016). Above-ground herbivory generally stimulates the cycling of nutrients by decomposers in the soil (A'Bear et al., 2014), which could partly explain increases in the $\mathrm{N}: \mathrm{P}$ ratios of plant tissues infested by aphids in the current study.

It was hypothesized that the abundance of AMF taxa within the AMF community would be impacted by aphid presence, and there was a marginal increase in the abundance of Gigasporaceae under aphid infestation of the host plant. A recent metaanalysis revealed that members of this family are tolerant to fertilizer input disturbances, suggesting a role aside from nutrient acquisition, perhaps in plant defense (van der Heyde et al., 2017b). Species indicator analysis may also identify taxa affected by treatments, however, as low abundance taxa typically score as poor indicators, the results of this method may differ from those investigating relative abundances (Longa et al., 2017). None of the AMF VTs were indicators of either treatment, but several total fungi amplicon OTUs were significant indicators of aphid presence or absence. Currently, it is unclear whether these fungi are responding to changes in nutrient availability, whether the plant recruits them in response to aphid feeding to aid with defense (Kong et al., 2016; Pineda et al., 2017), or whether the recruitment of specific soil microbes ultimately benefits the aphid (Kim et al., 2016).

No clear effects of aphid presence were found on community composition, perhaps as a longer period of top down pressure is required to impact this metric. For example, the effects of grazing by large vertebrates on AMF community structure are 
strongly linked to the length of the grazing (van der Heyde et al., 2017a). However, as plant communities are removed regularly in cereal systems, and aphid feeding is seasonal (Blackman and Eastop, 2000), only a relatively short window is available for these interactions to occur. Plot location, grain $\mathrm{P}$ concentration and AMF abundance as well as community composition were tightly linked in the current study. AMF communities may be associated with environmental and nutritional gradients in soil systems (Bainard et al., 2014; Horn et al., 2014; Guo et al., 2016; Yao et al., 2018) which also likely reflects the spatial differences measured in above-ground plant nutrition and AMF physiology here. Although care was taken to reduce the spread of plots across the slope of the site, these spatial differences highlight the importance of environmental heterogeneity within relatively small distances (less than $10 \mathrm{~m}$ ) in field sites, and this could have contributed to masking top down effects of aphids on community composition in the current study. Whether the associations between AMF community composition and plant $\mathrm{Si}$ are due to AMF uptake of Si (Garg and Bhandari, 2016; Frew et al., 2017), or an artifact of AMF responses to soil pH gradients or water availability (Bainard et al., 2014) requires further study.

\section{CONCLUSION}

Aphids increased the evenness of the entire fungal community within plant roots, and also tended to increase the level of vesicles and abundance of the AMF family Gigasporaceae. Whether these increases are due to increased $\mathrm{C}$ allocation below-ground by plants attempting to increase nutrient uptake, or the active selection of fungal taxa in response to herbivory requires elucidation. Whether these changes in the below-ground soil community feed back into altered aphid performance is currently unclear, but the response of agriculturally relevant fungal communities to top-down effects of herbivory suggests that above-below-ground community feedback could occur in agricultural systems.

\section{REFERENCES}

A'Bear, A. D., Johnson, S. N., and Jones, T. H. (2014). Putting the 'upstairsdownstairs' into ecosystem service: what can aboveground-belowground ecology tell us? Biol. Control 75, 97-107. doi: 10.1016/j.biocontrol.2013.10.004

Ba, L., Ning, J. X., Wang, D. L., Facelli, E., Facelli, J. M., Yang, Y. N., et al. (2012). The relationship between the diversity of arbuscular mycorrhizal fungi and grazing in a meadow steppe. Plant Soil 352, 143-156. doi: 10.1007/s11104-011-0985-6

Babikova, Z., Gilbert, L., Bruce, T., Dewhirst, S. Y., Pickett, J. A., and Johnson, D. (2014). Arbuscular mycorrhizal fungi and aphids interact by changing host plant quality and volatile emission. Funct. Ecol. 28, 375-385. doi: 10.1111/13652435.12181

Babikova, Z., Gilbert, L., Bruce, T. J. A., Birkett, M., Caulfield, J. C., Woodcock, C., et al. (2013). Underground signals carried through common mycelial networks warn neighbouring plants of aphid attack. Ecol. Lett. 16, 835-843. doi: 10.1111/ ele. 12115

Bainard, L. D., Bainard, J. D., Hamel, C., and Gan, Y. (2014). Spatial and temporal structuring of arbuscular mycorrhizal communities is differentially influenced

\section{DATA AVAILABILITY}

The raw sequence datasets for this study are available in the European Nucleotide Archive accession number PRJEB31469. The datasets for this study are available in the Dryad digital depository (doi: 10.5061/dryad.864pt1f/1).

\section{AUTHOR CONTRIBUTIONS}

TW, AH, SH, and JF contributed to the experimental design of the study. TW conducted the experiments and analyzed the data with consultation of the bioinformatics analysis from J-PM. All authors contributed to the writing of the manuscript.

\section{FUNDING}

This work was funded by the Biotechnology and Biological Sciences Research Council (BBSRC) United Kingdom, Doctoral Training Partnership grant (BB/J014443/1).

\section{ACKNOWLEDGMENTS}

We thank the RSK A.D.A.S Ltd. (High Mowthorpe, North Yorkshire, United Kingdom), in particular Dr. Kate Storer for advice and facilitation of the field study reported. We also thank members of the Dr. Thorunn Helgason group, particularly Dr. Susannah Bird and Phillip Brailey for advice and facilitation regarding sequencing and bioinformatics analysis. This work was derived from the work presented in a Ph.D. thesis of Wilkinson (2018).

\section{SUPPLEMENTARY MATERIAL}

The Supplementary Material for this article can be found online at: https://www.frontiersin.org/articles/10.3389/fpls.2019.00895/ full\#supplementary-material

by abiotic factors and host crop in a semi-arid prairie agroecosystem. FEMS Microbiol. Ecol. 88, 333-344. doi: 10.1111/1574-6941.12300

Barrett, G., Campbell, C. D., Fitter, A. H., and Hodge, A. (2011). The arbuscular mycorrhizal fungus Glomus hoi can capture and transfer nitrogen from organic patches to its associated host plant at low temperature. Appl. Soil Ecol. 48, 102-105. doi: 10.1016/j.apsoil.2011.02.002

Barto, E. K., and Rillig, M. C. (2010). Does herbivory really suppress mycorrhiza? a meta-analysis. J. Ecol. 98, 745-753. doi: 10.1111/j.1365-2745.2010. 01658.x

Battaglia, D., Bossi, S., Cascone, P., Digilio, M. C., Prieto, J. D., Fanti, P., et al. (2013). Tomato below ground-above ground interactions: Trichoderma longibrachiatum affects the performance of Macrosiphum euphorbiae and its natural antagonists. Mol. Plant Microbe Interact. 26, 1249-1256. doi: 10.1094/ mpmi-02-13-0059-r

Berruti, A., Desirò, A., Visentin, S., Zecca, O., and Bonfante, P. (2017). ITS fungal barcoding primers versus $18 \mathrm{~S}$ AMF-specific primers reveal similar AMF-based diversity patterns in roots and soils of three mountain vineyards. Environ. Microbiol. Rep. 9, 658-667. doi: 10.1111/1758-2229.12574 
Blackman, R., and Eastop, V. (2000). Aphids on the World's Crops an Identification and Information Guide, (2nd Edn). Hoboken, NJ: John Wiley \& Sons Ltd.

Boyetchko, S. M., and Tewari, J. P. (1995). Susceptibility of barley cultivars to vesicular arbuscular mycorrhizal fungi. Can. J. Plant Sci. 75:269. doi: 10.4141/ cjps95-048

Brundrett, M., Melville, L., and Peterson, L. (1994). Practical methods in mycorrhiza research. in Proceedings of the Practical Methods in Mycorrhiza Research: Based on a Workshop Organized in Conjuction With the Ninth North American Conference on Mycorrhizae Waterloo, ON: Mycologue Publications.

Cabral, C., Wollenweber, B., António, C., Rodrigues, A. M., and Ravnskov, S. (2018). Aphid infestation in the phyllosphere affects primary metabolic profiles in the arbuscular mycorrhizal hyphosphere. Sci. Rep. 8:14442. doi: 10.1038/ s41598-018-32670-1

Caporaso, J. G., Kuczynski, J., Stombaugh, J., Bittinger, K., Bushman, F. D., Costello, E. K., et al. (2010). QIIME allows analysis of high-throughput community sequencing data. Nat. Methods 7, 335-336. doi: 10.1038/nmeth.f. 303

Core Team, R. (2016). R: A Language and Environment for Statistical Computing. Vienna: R Foundation for Statistical Computing.

Dias, P. A. S., Sampaio, M. V., Rodrigues, M. P., Korndörfer, A. P., Oliveira, R. S. Ferreira, S. E., et al. (2014). Induction of resistance by silicon in wheat plants to alate and apterous morphs of Sitobion avenae (Hemiptera: Aphididae). Environ. Entomol. 43, 949-956. doi: 10.1603/en13234

Dumbrell, A. J., Ashton, P. D., Aziz, N., Feng, G., Nelson, M., Dytham, C., et al. (2011). Distinct seasonal assemblages of arbuscular mycorrhizal fungi revealed by massively parallel pyrosequencing. New Phytol. 190, 794-804. doi: 10.1111/j. 1469-8137.2010.03636.x

Edgar, R. C. (2010). Search and clustering orders of magnitude faster than BLAST. Bioinformatics 26, 2460-2461. doi: 10.1093/bioinformatics/ btq461

Fitter, A. H., Helgason, T., and Hodge, A. (2011). Nutritional exchange in the arbuscular mycorrhizal symbiosis: implications for sustainable agriculture. Fungal Biol. Rev. 25, 68-72. doi: 10.1016/j.fbr.2011.01.002

Frew, A., Powell, J. R., Allsopp, P. G., Sallam, N., and Johnson, S. N. (2017). Arbuscular mycorrhizal fungi promote silicon accumulation in plant roots, reducing the impacts of root herbivory. Plant Soil 419, 423-433. doi: 10.1007/ s11104-017-3357-z

Gange, A. (2007). "Insect-mycorrhizal interactions: patterns, processes, and consequences," in Ecological Communities: Plant Mediation in Indirect Interaction Webs, eds T. Ohgushi, T. Craig, and P. Price (Cambridge: Cambridge University Press).

Gange, A. C., and West, H. M. (1994). Interactions between arbuscular mycorrhizal fungi and foliar feeding insects in Plantago lanceolata L. New Phytol. 128, 79-87. doi: $10.1111 /$ j.1469-8137.1994.tb03989.x

Garcia, I., and Mendoza, R. (2012). Impact of defoliation intensities on plant biomass, nutrient uptake and arbuscular mycorrhizal symbiosis in Lotus tenuis growing in a saline-sodic soil. Plant Biol. 14, 964-971. doi: 10.1111/j.1438-8677. 2012.00581.x

Gardes, M., and Bruns, T. D. (1993). ITS primers with enhanced specificity for Basidiomycetes - application to the identification of mycorrhizae and rusts. Mol. Ecol. 2, 113-118. doi: 10.1111/j.1365-294X.1993.tb00005.x

Garg, N., and Bhandari, P. (2016). Silicon nutrition and mycorrhizal inoculations improve growth, nutrient status, $\mathrm{K}+/ \mathrm{Na}+$ ratio and yield of Cicer arietinum $\mathrm{L}$. genotypes under salinity stress. Plant Growth Regul. 78, 371-387. doi: 10.1007/ s10725-015-0099-x

Gehring, C., and Bennett, A. (2009). Mycorrhizal fungal-plant-insect interactions: the importance of a community approach. Environ. Entomol. 38, 93-102. doi: 10.1603/022.038.0111

Gosling, P., Hodge, A., Goodlass, G., and Bending, G. D. (2006). Arbuscular mycorrhizal fungi and organic farming. Agric. Ecosyst. Environ. 113, 17-35. doi: 10.1016/j.agee.2005.09.009

Grace, E. J., Cotsaftis, O., Tester, M., Smith, F. A., and Smith, S. E. (2009). Arbuscular mycorrhizal inhibition of growth in barley cannot be attributed to extent of colonization, fungal phosphorus uptake or effects on expression of plant phosphate transporter genes. New Phytol. 181:938-949. doi: 10.1111/j. 1469-8137.2008.02720.x

Guo, Y. J., Du, Q. F., Li, G. D., Ni, Y., Zhang, Z., Ren, W. B., et al. (2016). Soil phosphorus fractions and arbuscular mycorrhizal fungi diversity following long-term grazing exclusion on semi-arid steppes in inner Mongolia. Geoderma 269, 79-90. doi: 10.1016/j.geoderma.2016.01.039

Hartley, S. E., and Gange, A. C. (2009). Impacts of plant symbiotic fungi on insect herbivores: mutualism in a multitrophic context. Annu. Rev. Entomol. 54, 323-342. doi: 10.1146/annurev.ento.54.110807.090614

Hartmann, M., Frey, B., Mayer, J., Mäder, P., and Widmer, F. (2015). Distinct soil microbial diversity under long-term organic and conventional farming. ISME J. 9, 1177-1194. doi: 10.1038/ismej.2014.210

Hawkes, C. V., Hartley, I. P., Ineson, P., and Fitter, A. H. (2008). Soil temperature affects carbon allocation within arbuscular mycorrhizal networks and carbon transport from plant to fungus. Glob. Change Biol. 14, 1181-1190. doi: 10.1111/ j.1365-2486.2007.01535.x

Hodge, A. (2001). Arbuscular mycorrhizal fungi influence decomposition of, but not plant nutrient capture from, glycine patches in soil. New Phytol. 151, 725-734. doi: 10.1046/j.0028-646x.2001.00200.x

Hodge, A., Campbell, C. D., and Fitter, A. H. (2001). An arbuscular mycorrhizal fungus accelerates decomposition and acquires nitrogen directly from organic material. Nature 413, 297-299. doi: 10.1038/35095041

Hodge, A., and Fitter, A. H. (2010). Substantial nitrogen acquisition by arbuscular mycorrhizal fungi from organic material has implications for $\mathrm{N}$ cycling. Proc. Nat. Acad. Sci. U.S.A. 107, 13754-13759. doi: 10.1073/pnas.1005874107

Hodge, A., and Fitter, A. H. (2013). Microbial mediation of plant competition and community structure. Funct. Ecol. 27, 865-875. doi: 10.1111/1365-2435.12002

Horn, S., Caruso, T., Verbruggen, E., Rillig, M. C., and Hempel, S. (2014). Arbuscular mycorrhizal fungal communities are phylogenetically clustered at small scales. ISME J. 8, 2231-2242. doi: 10.1038/ismej.2014.72

Hoysted, G., Bell, C., Lilley, C., and Urwin, P. (2018). Aphid colonization affects potato root exudate composition and the hatching of a soil borne pathogen. Front. Plant Sci. 9:1278. doi: 10.3389/fpls.2018.01278

Ihrmark, K., Bödeker, I. T. M., Cruz-Martinez, K., Friberg, H., Kubartova, A., Schenck, J., et al. (2012). New primers to amplify the fungal ITS2 region - evaluation by 454-sequencing of artificial and natural communities. FEMS Microbiol. Ecol. 82, 666-677. doi: 10.1111/j.1574-6941.2012.01437.x

Jacott, C. N., Murray, J. D., and Ridout, C. J. (2017). Trade-offs in arbuscular mycorrhizal symbiosis: disease resistance, growth responses and perspectives for crop breeding. Agronomy 7:75. doi: 10.3390/agronomy7040075

Jansa, J., Mozafar, A., Anken, T., Ruh, R., Sanders, I. R., and Frossard, E. (2002). Diversity and structure of AMF communities as affected by tillage in a temperate soil. Mycorrhiza 12, 225-234. doi: 10.1007/s00572-0020163-z

Jansa, J., Smith, F. A., and Smith, S. E. (2008). Are there benefits of simultaneous root colonization by different arbuscular mycorrhizal fungi? New Phytol. 177, 779-789. doi: 10.1111/j.1469-8137.2007.02294.x

Jiang, S., Liu, Y., Luo, J., Qin, M., Johnson, N. C., Öpik, M., et al. (2018). Dynamics of arbuscular mycorrhizal fungal community structure and functioning along a nitrogen enrichment gradient in an alpine meadow ecosystem. New Phytol. 220, 1222-1235. doi: 10.1111/nph.15112

Jones, D. L., Hodge, A., and Kuzyakov, Y. (2004). Plant and mycorrhizal regulation of rhizodeposition. New Phytol. 163, 459-480. doi: 10.1111/j.1469-8137.2004. 01130.x

Karasawa, T., Hodge, A., and Fitter, A. H. (2012). Growth, respiration and nutrient acquisition by the arbuscular mycorrhizal fungus Glomus mosseae and its host plant Plantago lanceolata in cooled soil. Plant Cell Environ. 35, 819-828. doi: 10.1111/j.1365-3040.2011.02455.x

Katayama, N., Silva, A. O., Kishida, O., Ushio, M., Kita, S., and Ohgushi, T. (2014). Herbivorous insect decreases plant nutrient uptake: the role of soil nutrient availability and association of below-ground symbionts. Ecol. Entomol. 39, 511-518. doi: 10.1111/een. 12125

Keymer, A., and Gutjahr, C. (2018). Cross-kingdom lipid transfer in arbuscular mycorrhiza symbiosis and beyond. Curr. Opin. Plant Biol. 44, 137-144. doi: 10.1016/j.pbi.2018.04.005

Kim, B., Song, G. C., and Ryu, C. M. (2016). Root exudation by aphid leaf infestation recruits root-associated Paenibacillus spp. to lead plant insect susceptibility. J. Microbiol. Biotechnol. 26, 549-557. doi: 10.4014/jmb.1511. 11058

Kõljalg, U., Nilsson, R. H., Abarenkov, K., Tedersoo, L., Taylor, A. F. S., Bahram, M., et al. (2013). Towards a unified paradigm for sequence-based identification of fungi. Mol. Ecol. 22, 5271-5277. doi: 10.1111/mec.12481 
Kong, H. G., Kim, B. K., Song, G. C., Lee, S., and Ryu, C.-M. (2016). Aboveground whitefly infestation-mediated reshaping of the root microbiota. Front. Microbiol. 7:1314. doi: 10.3389/fmicb.2016.01314

Kos, M., Tuijl, M. A. B., De Roo, J., Mulder, P. P. J., and Bezemer, T. M. (2015). Species-specific plant-soil feedback effects on above-ground plantinsect interactions. J. Ecol. 103, 904-914. doi: 10.1111/1365-2745.12402

Kostenko, O., van de Voorde, T. F. J., Mulder, P. P. J., van der Putten, W. H., and Bezemer, T. M. (2012). Legacy effects of aboveground-belowground interactions. Ecol. Lett. 15, 813-821. doi: 10.1111/j.1461-0248.2012.01801.x

Lee, J., Lee, S., and Young, J. P. W. (2008). Improved PCR primers for the detection and identification of arbuscular mycorrhizal fungi. FEMS Microbiol. Ecol. 65, 339-349. doi: 10.1111/j.1574-6941.2008.00531.x

Leigh, J., Hodge, A., and Fitter, A. H. (2009). Arbuscular mycorrhizal fungi can transfer substantial amounts of nitrogen to their host plant from organic material. New Phytol. 181, 199-207. doi: 10.1111/j.1469-8137.2008.02630.x

Longa, C. M. O., Nicola, L., Antonielli, L., Mescalchin, E., Zanzotti, R., Turco, E., et al. (2017). Soil microbiota respond to green manure in organic vineyards. J. Appl. Microbiol. 123, 1547-1560. doi: 10.1111/jam.13606

Lugtenberg, B. J. J., Caradus, J. R., and Johnson, L. J. (2016). Fungal endophytes for sustainable crop production. FEMS Microbiol. Ecol. 92:fiw194. doi: 10.1093/ femsec/fiw194

Malik, R. J., Dixon, M. H., and Bever, J. D. (2016). Mycorrhizal composition can predict foliar pathogen colonization in soybean. Biol. Control 103, 46-53. doi: 10.1016/j.biocontrol.2016.08.004

Manoharan, L., Rosenstock, N. P., Williams, A., and Hedlund, K. (2017). Agricultural management practices influence AMF diversity and community composition with cascading effects on plant productivity. Appl. Soil Ecol. 115, 53-59. doi: 10.1016/j.apsoil.2017.03.012

Maurya, A. K., Kelly, M. P., Mahaney, S. M., and Gomez, S. K. (2018). Arbuscular mycorrhizal symbiosis alters plant gene expression and aphid weight in a tripartite interaction. J. Plant Interact. 13, 294-305. doi: 10.1080/17429145. 2018.1475020

McKirdy, S. J., Jones, R. A. C., and Nutter, F. W. (2002). Quantification of yield losses caused by barley yellow dwarf virus in wheat and oats. Plant Dis. 86, 769-773. doi: 10.1094/pdis.2002.86.7.769

Meir, A., and Hunter, D. (2018a). Arbuscular mycorrhizal fungi mediate herbivoreinduction of plant defenses differently above and belowground. Oikos 127, 1759-1775. doi: 10.1111/oik.05402

Meir, A., and Hunter, M. (2018b). Mycorrhizae alter toxin sequestration and performance of two specialist herbivores. Front. Ecol. Evol. 6:33. doi: 10.3389/ fevo.2018.00033

Milcu, A., Bonkowski, M., Collins, C. M., and Crawley, M. J. (2015). Aphid honeydew-induced changes in soil biota can cascade up to tree crown architecture. Pedobiologia 58, 119-127. doi: 10.1016/j.pedobi.2015.07.002

Murphy, B. R., Doohan, F. M., and Hodkinson, T. R. (2015). Fungal root endophytes of a wild barley species increase yield in a nutrient-stressed barley cultivar. Symbiosis 65, 1-7. doi: 10.1007/s13199-015-0314-6

Nowak, H., and Komor, E. (2010). How aphids decide what is good for them: experiments to test aphid feeding behaviour on Tanacetum vulgare (L.) using different nitrogen regimes. Oecologia 163, 973-984. doi: 10.1007/s00442-010$1652-y$

Öpik, M., Vanatoa, A., Vanatoa, E., Moora, M., Davison, J., Kalwij, J. M., et al. (2010). The online database MaarjAM reveals global and ecosystemic distribution patterns in arbuscular mycorrhizal fungi (Glomeromycota). New Phytol. 188, 223-241. doi: 10.1111/j.1469-8137.2010.03334.x

Perotto, S., and Bonfante, P. (1997). Bacterial associations with mycorrhizal fungi: close and distant friends in the rhizosphere. Trends Microbiol. 5, 496-501. doi: 10.1016/S0966-842X(97)01154-2

Pineda, A., Kaplan, I., and Bezemer, T. M. (2017). Steering soil microbiomes to suppress aboveground insect pests. Trends Plant Sci. 22, 770-778. doi: 10.1016/ j.tplants.2017.07.002

Pozo, M. J., Cordier, C., Dumas-Gaudot, E., Gianinazzi, S., Barea, J. M., and AzcónAguilar, C. (2002). Localized versus systemic effect of arbuscular mycorrhizal fungi on defence responses to Phytophthora infection in tomato plants. J. Exp. Bot. 53, 525-534. doi: 10.1093/jexbot/53.368.525

Reidinger, S., Ramsey, M. H., and Hartley, S. E. (2012). Rapid and accurate analyses of silicon and phosphorus in plants using a portable $\mathrm{X}$-ray fluorescence spectrometer. New Phytol. 195, 699-706. doi: 10.1111/j.1469-8137.2012.04179.

Sandstrom, J., Telang, A., and Moran, N. A. (2000). Nutritional enhancement of host plants by aphids - a comparison of three aphid species on grasses. J. Insect Physiol. 46, 33-40. doi: 10.1016/s0022-1910(99)0 0098-0

Sikes, B. A., Cottenie, K., and Klironomos, J. N. (2009). Plant and fungal identity determines pathogen protection of plant roots by arbuscular mycorrhizas. J. Ecol. 97, 1274-1280. doi: 10.1111/j.1365-2745.2009.01557.x

Simon, A. L., Wellham, P. A. D., Aradottir, G. I., and Gange, A. C. (2017). Unravelling mycorrhiza-induced wheat susceptibility to the English grain aphid Sitobion avenae. Sci. Rep. 7:46497. doi: 10.1038/srep46497

Sinka, M., Jones, T. H., and Hartley, S. E. (2009). Collembola respond to aphid herbivory but not to honeydew addition. Ecol. Entomol. 34, 588-594. doi: 10. 1111/j.1365-2311.2009.01106.x

Smith, F. A., Grace, E. J., and Smith, S. E. (2009). More than a carbon economy: nutrient trade and ecological sustainability in facultative arbuscular mycorrhizal symbioses. New Phytol. 182, 347-358. doi: 10.1111/j.1469-8137. 2008.02753.x

Smith, S., and Read, D. (2008). Mycorrhizal Symbiosis. Cambridge, MA: Academic Press.

Tao, L. L., and Hunter, M. D. (2012). Does anthropogenic nitrogen deposition induce phosphorus limitation in herbivorous insects? Glob. Change Biol. 18:1843. doi: 10.1111/j.1365-2486.2012.02645.x

Thirkell, T. J., Cameron, D. D., and Hodge, A. (2016). Resolving the 'nitrogen paradox' of arbuscular mycorrhizas: fertilization with organic matter brings considerable benefits for plant nutrition and growth. Plant Cell Environ. 39, 1683-1690. doi: 10.1111/pce.12667

Thirkell, T. J., Charters, M. D., Elliott, A. J., Sait, S. M., and Field, K. J. (2017). Are mycorrhizal fungi our sustainable saviours? considerations for achieving food security. J. Ecol. 105, 921-929. doi: 10.1111/1365-2745.12788

Thompson, G. A., and Goggin, F. L. (2006). Transcriptomics and functional genomics of plant defence induction by phloem-feeding insects. J. Exp. Bot. 57, 755-766. doi: 10.1093/jxb/erj135

Tomczak, V. V., and Müller, C. (2017). Influence of arbuscular mycorrhizal stage and plant age on the performance of a generalist aphid. J. Insect Physiol. 98, 258-266. doi: 10.1016/j.jinsphys.2017.01.016

Ueda, K., Tawaraya, K., Murayama, H., Sato, S., Nishizawa, T., Toyomasu, T., et al. (2013). Effects of arbuscular mycorrhizal fungi on the abundance of foliar-feeding insects and their natural enemy. Appl. Entomol. Zool. 48, 79-85. doi: 10.1007/s13355-012-0155-1

van der Heyde, M., Bennett, J. A., Pither, J., and Hart, M. (2017a). Longterm effects of grazing on arbuscular mycorrhizal fungi. Agric. Ecosyst. Environ. 243, 27-33. doi: 10.1016/j.agee.2017.04.003

van der Heyde, M., Ohsowski, B., Abbott, L. K., and Hart, M. (2017b). Arbuscular mycorrhizal fungus responses to disturbance are contextdependent. Mycorrhiza 27, 431-440. doi: 10.1007/s00572-016-0759-3

Vannette, R. L., and Hunter, M. D. (2014). Genetic variation in plant below-ground response to elevated $\mathrm{CO}_{2}$ and two herbivore species. Plant Soil 384, 303-314. doi: 10.1007/s11104-014-2203-9

Vasar, M., Andreson, R., Davison, J., Jairus, T., Moora, M., Remm, M., et al. (2017). Increased sequencing depth does not increase captured diversity of arbuscular mycorrhizal fungi. Mycorrhiza 27, 761-773. doi: 10.1007/s00572-0170791-y

Vestergård, M., Bjørnlund, L., and Christensen, S. (2004). Aphid effects on rhizosphere microorganisms and microfauna depend more on barley growth phase than on soil fertilization. Oecologia 141, 84-93. doi: 10.1007/s00442-0041651-y

Vierheilig, H., Coughlan, A. P., Wyss, U., and Piché, Y. (1998). Ink and vinegar, a simple staining technique for arbuscular-mycorrhizal fungi. Appl. Environ. Microbiol. 64, 5004-5007.

Wallace, L. L. (1987). Mycorrhizas in grasslands - interactions of ungulates, fungi and drought. New Phytol. 105, 619-632. doi: 10.1111/j.1469-8137.1987.tb00900. $\mathrm{x}$

Wamberg, C., Christensen, S., and Jakobsen, I. (2003). Interaction between foliarfeeding insects, mycorrhizal fungi, and rhizosphere protozoa on pea plants Pedobiologia 47, 281-287. doi: 10.1078/0031-4056-00191 
Wetzel, K., Silva, G., Matczinski, U., Oehl, F., and Fester, T. (2014). Superior differentiation of arbuscular mycorrhizal fungal communities from till and notill plots by morphological spore identification when compared to T-RFLP. Soil Biol. Biochem. 72, 88-96. doi: 10.1016/j.soilbio.2014.01.033

White, T. J., Bruns, T. D., Lee, S., and Taylor, J. (1990). “Amplification and direct sequencing of fungal ribosomal RNA genes for phylogenetics," in PCR Protocols: A Guide to Methods and Applications, eds M. A. Innis, D. H. Gelfland, J. J. Sninsky, and T. J. White (Cambridge, MA: Academic Press), 315-322. doi: 10.1016/b978-0-12-372180-8.50042-1

Wilkinson, T. D. J. (2018). Interactions between above and below ground symbionts: Implications for food security. York: University of York. Ph.D. thesis.

Wilkinson, T. D. J., Ferrari, J., Hartley, S. E., and Hodge, A. (2019). Aphids can acquire the nitrogen delivered to plants by arbuscular mycorrhizal fungi. Funct. Ecol. 33, 576-586. doi: 10.1111/1365-2435.13283

Williams, A., Birkhofer, K., and Hedlund, K. (2014). Above- and belowground interactions with agricultural management: effects of soil microbial communities on barley and aphids. Pedobiologia 57, 67-74. doi: 10.1016/j. pedobi.2014.01.004

Wurst, S., Dugassa-Gobena, D., Langel, R., Bonkowski, M., and Scheu, S. (2004). Combined effects of earthworms and vesicular-arbuscular mycorrhizas on plant and aphid performance. New Phytol. 163, 169-176. doi: 10.1111/j.1469-8137. 2004.01106.x

Yang, H., Dai, Y., Wang, X., Zhang, Q., Zhu, L., and Bian, X. (2014). Meta-analysis of interactions between arbuscular mycorrhizal fungi and biotic stressors of plants. Sci. World J. 2014:746506. doi: 10.1155/2014/746506

Yao, L. H., Wang, D. J., Kang, L., Wang, D. K., Zhang, Y., Hou, X. Y., et al. (2018). Effects of fertilizations on soil bacteria and fungi communities in a degraded arid steppe revealed by high through-put sequencing. PeerJ 6:e4623. doi: $10.7717 /$ peerj.4623

Conflict of Interest Statement: The authors declare that the research was conducted in the absence of any commercial or financial relationships that could be construed as a potential conflict of interest.

Copyright (c) 2019 Wilkinson, Miranda, Ferrari, Hartley and Hodge. This is an openaccess article distributed under the terms of the Creative Commons Attribution License (CC BY). The use, distribution or reproduction in other forums is permitted, provided the original author(s) and the copyright owner(s) are credited and that the original publication in this journal is cited, in accordance with accepted academic practice. No use, distribution or reproduction is permitted which does not comply with these terms. 